\title{
Fertility Differentials in Kenya: The Effect of Female Migration
}

\author{
Charles Ochola Omondi \\ Department of Geography \\ Maseno University \\ Kenya
}

\author{
E.H.O. Ayiemba \\ Department of Geography \\ University of Nairobi \\ Kenya
}

\begin{abstract}
This study uses the Kenya Demographic and Health Survey (KDHS) data conducted in 1988/89. The hypothesis of the paper is that women who migrate tend to maximise their other lifetime aspirations at the expense of their reproductive roles and performance. That is, female migrants are involved in behaviours and practices that negatively influence fertility relative to non-migrants. The analysis shows that through the influence of migration on fertility, reproductive behaviour and performance is modified; migration is a mechanism through which the changes observed in fertility behaviour and levels can be explained. The influence of migration on fertility levels is estimated using two procedures: the comparison of the mean $C E B$ and multivariate analysis. The study demonstrated that there is an inverse relationship between migration and the number of children ever born.
\end{abstract}

\section{Introduction}

Differentials in fertility behaviour and levels in different areas, and among population strata or characteristics, have been one of the most pervasive findings in demography (Cochrane, 1989). One major cause of the differentials is the association between the migration process and fertility behaviour. Research has shown that women who migrate to new environments where education is high, jobs are available, and living standards high, show almost universally lower fertility than their counterparts in areas of low education standards, non-availability of jobs or otherwise blue collar jobs, and low standards of living (Goldstein and Goldstein, 1983).

Although these relationships are often weakened after introducing controls for different background characteristics and other factors influencing fertility, they generally tend to remain statistically significant. They do, however, vary substantially in degree from one region and/or country to another, a fact that has prompted analysts to believe that the ultimate explanation for fertility behaviour must be sought in cultural and/or institutional processes specific to an area. 
An alternative view, however, is that differentials are exaggerated in the course of the changes experienced in fertility behaviour, as some groups lead social change while others lag behind, occasioned by one major social change factor, the migration process. Thus, by advancing a comprehensive framework to analyse the association between migration and fertility levels, which controls for different background characteristics of women, as well as the fertility intermediate variables of marriage and contraceptive behaviour, it should be possible to understand further the patterns of fertility differentials and levels in Kenya.

Identification of fertility differentials due to migration, especially where there is a fast fertility decline, would suggest that migrants may have moved to realise their desired family building preferences, and may serve as innovators who can impart ideas concerning fertility behaviour and family size to other population subgroups in whichever environments or settlements (Brockerhoff and Yang, 1995). Moreover, for governments seeking comprehensive national population policy, such findings may help in formulating policy related to population dynamics in general and migration-fertility interrelationships in particular.

\section{Data Source}

This paper uses data from the Kenya Demographic and Health Survey (KDHS). The Demographic and Health Survey (DHS) model questionnaire used for Kenya in 1989 has a number of questions on the background characteristics of women and their fertility variables that can be used to underscore the relationship between migration and fertility behaviour (KDHS, 1989).

\section{Explanatory Variables}

\section{Education Level}

Female education is the most widely reported variable that shows a consistent negative association with fertility. Both the demographic transition literature and contemporary research in developing areas have cited education, after age, as the single most important variable affecting fertility. Cochrane (1989) wrote a comprehensive report on the effects of education and residential characteristics on fertility, concluding that, to estimate the effect of education on fertility, it is necessary to eliminate spurious correlations between education and the other fertility determinants, such as age and residence. Furthermore, evidence shows that level of education affects both fertility and migration, with higher education being associated with lower fertility and higher levels of migration often directly related to higher education (Goldstein and Goldstein, 1983; Cochrane, 1989; Hervitz, 1985; Brockerhoff and Eu, 1993). 
The KDHS data that are used here allow assessment of the interrelations between the variables to determine whether the migration process has an effect on fertility when education is controlled. Since female education appears to be the most influential fertility determinant, it is relevant to understand how it interacts with migration and fertility proximate determinants to affect fertility. The categories used for the level of education are non-schooling, primary and secondary plus, representing the respondents completed years of schooling.

\section{Work Status}

The demographic transition theory serves as the major framework for most macro-level investigations of fertility dynamics (Findley, 1982). This classic interpretation of the European fertility transition suggests that nonagricultural labour-force participation intervenes between economic development and fertility. Economic development is associated with an increase in education and occupational opportunities for women that compete with fertility-inhibiting factors to influence fertility. This relationship between female employment and fertility holds in developing countries, although regional variations are noticeable (Anker and Knowles, 1982). Together with other aspects of the development process, such as migration, these opportunities are expected to affect fertility via the proximate determinants.

Labour force participation and work status can be used in assessing fertility and migration jointly, although research findings on these variables have failed to point to a clear and consistent relation among them (Bongaarts, 1982). This is largely because of differences in definitions used in different places, especially between the developing and developed areas, and because, even when definitions are similar, they may have assumed that similarly categorised activities are in fact comparable in different contexts (Arnold and Blanc, 1990). However, this is not always so.

The KDHS categorized work status and occupation meaningfully within the national context (KDHS, 1989). Work status is a dichotomous variable that measures whether a woman is currently undertaking paid employment or not. Occupation is grouped into several categories: never worked agriculture, skilled and unskilled manual labour, sales and services, professional and clerical positions, and other occupations. The study uses work status in assessing the effect of migration on fertility because occupation characteristics were collected from husbands. Explanatory variable of whether a woman 'works' or 'does not work' is used for the analysis. 


\section{Place of Residence}

Basic to the understanding of the relation between migration and fertility is the effect of place of residence both at the time of the survey and at varied times in the period preceding migration, or at fixed points before the survey (Brockerhoff and $\mathrm{Eu}, 1993$ ). Studies have also indicated the powerful effect of urban residence in accounting for lower fertility levels. Urban residence may occur in the early stages of a woman's life or at later times, and the length of exposure or living in an area may also be of critical consideration (Goldstein and Goldstein, 1983).

The information collected in the KDHS allows a careful control of current place and duration of residence after respondents have reached age 15. Not only are data available on the urban and rural character of current places of residence, information is also provided on the character of previous residences and the length of time spent in such places. This, in fact, forms the basis for the definition of the migration variable used throughout this analysis. Also, the analysis is undertaken in terms of more than a simple urban and rural dichotomy since the KDHS questionnaire makes a distinction among city, town, and village. Town and city make up the urban component, while village is similar to the rural classification.

\section{Region/Province of Residence}

Analysis of geopolitical units in fertility studies has been concerned with the measurement of socio-economic and cultural factors (Wortham, 1995). In Kenya, extensive fertility analyses have tried to focus on cross-sectional variations in levels and patterns in relation to socio-economic and environmental influences by provinces (Brass and Jolly, 1993). The DHS data show significant correlation between fertility differentials and variables representing socio-economic features and mortality of sub-regions within Kenya (KDHS, 1989).

Since the study aims at exploring the association between migration and fertility, province of residence is adopted as one of the explanatory variables. All the provinces of Kenya, except North Eastern, which was not surveyed, are included in the analysis. Apart from identifying the structural patterns within the Kenyan community, the provincial divisions are appropriate in understanding the socio-economic and cultural effects of migration on fertility behaviour and levels. It is important also to note that these provinces can be said to be representative of ethnic distribution, especially for the three large ethnic groups in Kenya.

\section{Ethnicity}

Ethnicity is an important proxy of cultural factors affecting fertility since it encompasses values and norms that govern the behavioural and 
psychological issues affecting fertility. It may also reflect the openness to the influences and/or adherence to other cultures due to interactions from different areas and/or regions. Culture can also affect fertility indirectly through fertility proximate determinants, particularly age at first marriage, breast-feeding, contraceptive use and sexual behaviour.

In a number of societies or in national contexts, ethnic differentials are important in explaining demographic behaviour. Ethnic groups can be quite varied, and different groups may be at different stages of the fertility transition due to the process of cultural change. The influence of culture, which may itself reflect fundamental beliefs in religion or customs, which have developed in a particular community, can be pervasive and difficult to quantify.

\section{Marriage}

In almost all societies, the actual fertility of women is substantially lower than that which is biologically possible. Studies of fertility behaviour, based on data from the World Fertility Survey (WFS), have concluded that marital exposure is one of the means through which substantial changes in potential fertility are achieved (United Nations, 1984). Factors affecting marriage patterns, age at first marriage, proportion married, and patterns of marital dissolutions may have important influence on the overall level of fertility (Bongaarts, 1983). Migration may be an important factor in explaining fertility levels by influencing the different intermediate variables. Migration represents a break in social ties at the places of origin and destination, and may require a period of time before new ties can be developed at place of destination; it may contribute to changes in marital behaviour. From the various questions on marriage asked during the survey, this analysis defines several marital indices as explanatory variables to indicate the dynamism of marital behaviour within the context of the interrelationship under consideration.

\section{Contraception}

Studies have indicated the importance of differences of residence with respect to contraceptive knowledge and use (Robinson, 1992; Robinson and Harbison, 1995; Goldstein and Goldstein, 1983). If a woman leaving a rural area is 'rational' in her decision to leave, and innovative with respect to types of opportunities and challenges she is seeking in the urban place, she may also be more "modern" than the non-migrant at origin in terms of her contraceptive behaviour, and possibly even as modern as the woman who has spent her life in the urban locations. However, if a woman moves to the urban area because of pressures 'forcing' her out of the villages, she may bring with her not only high fertility values but also more limited knowledge and practice of contraceptive. In the urban area, she is not likely, in the short run, to change her attitudes and practices. 
Differences in attitudes towards contraception may also characterise women who move within and from the rural areas and those who move from and within urban areas. Migrants may be moving for more or less rational reasons, and their contraceptive behaviours may very well reflect a general rationality in behaviour that informs both fertility and migration.

\section{Methodology}

In defining the migration variable for the study, a woman's number of years lived in the current place of residence is taken into account. Those who answered 'always lived' are classified as non-migrants, whereas those whose answers were in terms of 'number of years lived in current place of residence' or 'length of time in the current place of residence', excluding those who answered 'visitor', are regarded as migrants. Cross-tabulation of these categories by the current place of residence gives rise to different migration groups. Migration status is defined in terms of migrants/nonmigrants and migration streams.

The flexibility of the definition and/or measurement of migration variable in the study allow a fuller exploitation of the relationship between migration and fertility where an aggregate measure like the children ever born (CEB) is used. Mean number of children ever born to women represents childbearing experience of a real age cohort and reflects current and past fertility behaviour. Besides, the use of CEB, by allowing identification of the fertility of migrants and non-migrants by background differentials and proximate variables, may suggest which migration status and characteristics are relevant for the understanding of fertility in a given country, region, or among a group of people. CEB does allow for the generation and generalisation of data and an understanding that can provide the basis for further analysis, particularly when one is using longitudinal data and approaches. CEB is thus used as the dependent variable.

The association between migration and fertility is analysed, first as a function of the migration process, the background characteristics of women, and the fertility proximate variables, and secondly as a function of the woman's background characteristics and fertility proximate variables, when migration status categories are controlled using the comparison of the mean and the multivariate analysis (OLS) technique.

\section{Comparison of the Mean}

The comparison of mean procedure is used to measure the difference in the mean number of children ever born (CEB) standardised by age for the different background characteristics. The means procedure calculates subgroup means and related univariate statistics for dependent variables within categories of one or more independent variables. The age-specific standardisation procedure compares the sizes of different age groups at a particular point in time in order to eliminate the influence of the differences 
in age by adjusting the actual size of each age group according to different ages.

\section{Age-specific Standardization}

The age standardization can be done by inferring the size of each cohort corresponding to an age group through the actual size of each age group and existing life table or by calculating the age standardisation as follows:

Assume the following hypothetical distribution of women by CEB for different population sub-groups ' $\mathrm{A}$ ' and ' $\mathrm{B}$ ' shown in Table-1 below.

Table 1: Unstandardized Mean CEB

\begin{tabular}{|c|c|c|c|c|c|c|c|c|}
\hline \multirow{4}{*}{$\begin{array}{l}\text { Age } \\
\text { Group }\end{array}$} & \multicolumn{2}{|c|}{ Sub-groups } & \multirow{3}{*}{$\begin{array}{r}\text { CEB } \\
\text { (2) }\end{array}$} & \multirow{4}{*}{$\begin{array}{r}\text { Mean } \\
{[2 / 1]} \\
(3)\end{array}$} & \multicolumn{2}{|c|}{ Sub-groups } & \multirow{4}{*}{$\begin{array}{c}\text { CEB } \\
\text { (5) }\end{array}$} & \multirow{4}{*}{$\begin{array}{r}\text { Mean [ } \\
5 / 4] \\
(6)\end{array}$} \\
\hline & \multirow{3}{*}{ (1) ${ }^{\prime A}$} & $\%$ & & & ${ }^{\prime} \mathrm{A}{ }^{\prime}$ & $\%$ & & \\
\hline & & Age dist. & & & (4) & Age & & \\
\hline & & & & & & & & \\
\hline $15-19$ & 1420 & 0.236 & 295 & 0.208 & 238 & 0.190 & 39 & 0.164 \\
\hline $20-24$ & 1205 & 0.200 & 1788 & 1.484 & 364 & 0.291 & 347 & 0.953 \\
\hline $25-29$ & 922 & 0.193 & 2715 & 2.945 & 260 & 0.208 & 546 & 2.100 \\
\hline $30-34$ & 880 & 0.146 & 4226 & 4.802 & 188 & 0.150 & 615 & 3.271 \\
\hline $35-39$ & 644 & 0.107 & 4067 & 6.315 & 97 & 0.078 & 450 & 4.639 \\
\hline $40-44$ & 561 & 0.093 & 4042 & 7.205 & 64 & 0.051 & 310 & 4.844 \\
\hline $45-49$ & 393 & 0.069 & 3220 & 8.193 & 37 & 0.030 & 174 & 4.703 \\
\hline All ages & 6025 & & 20353 & 3.378 & & 1250 & & 1.985 \\
\hline Mean CEB & & & & & & & & \\
\hline
\end{tabular}

From the results, women in group ' $\mathrm{A}$ ' have higher mean number of $\mathrm{CEB}$ than those in group ' $\mathrm{B}$ '. The result is due to differential in age composition of the two sub-groups of population considered. However, in order to agree or disagree with the observation, there is need to standardize mean CEB; that is, the computation of mean CEB for different groups (rural/urban women for example) is done assuming that they had the age distribution of the 'standard population'. In this analysis, the age standardization computation is undertaken for each group taking the overall population distribution of Kenya for each year as the 'standard population'. Computation of the standardized mean CEB takes the following form (Table-2).

Table 2: Computation of Age Standardized Mean CEB

\begin{tabular}{lrrrrr}
\hline $\begin{array}{l}\text { Age } \\
\text { Group }\end{array}$ & $\begin{array}{r}\text { CEB of } \\
\text { 'A' }\end{array}$ & $\begin{array}{r}\text { CEB } \\
\text { of } \\
\text { 'B' }\end{array}$ & $\begin{array}{r}\text { 'Standard } \\
\text { population' }\end{array}$ & $\begin{array}{r}\text { Expected } \\
\text { births for } \\
\text { 'A' }\end{array}$ & $\begin{array}{r}\text { Expected } \\
\text { births for } \\
\text { ' } \mathbf{B}^{\prime}\end{array}$ \\
\cline { 2 - 6 } & $(1)$ & $(2)$ & $(3)$ & $(4)$ & $(5)$ \\
\hline & & & & & \\
$15-19$ & 0.208 & 0.164 & 1659 & 345.072 & 272.076 \\
$20-24$ & 1.484 & 0.953 & 1569 & 2328.396 & 1495.257 \\
$25-29$ & 2.945 & 2.100 & 1182 & 3480.99 & 2482.2 \\
$30-34$ & 4.802 & 3.271 & 1068 & 5128.536 & 3493.428 \\
$35-39$ & 6.315 & 4.639 & 741 & 4679.415 & 3437.499 \\
\hline
\end{tabular}


32 African Population Studies Vol. $20 N^{\circ}$ 2/Etude de la population africaine vol. $20 n^{\circ} 2$

\begin{tabular}{|c|c|c|c|c|c|}
\hline $40-44$ & 7.205 & 4.844 & 625 & 4503.125 & 3027.5 \\
\hline 45049 & 8.193 & 4.703 & 430 & 3622.99 & 2022.29 \\
\hline All ages & & & 7274 & 23988.52 & 16230.25 \\
\hline \multicolumn{3}{|c|}{ Age standardized mean CEB } & & $3.2979(4 / 3)$ & $2.2313(5 / 3)$ \\
\hline
\end{tabular}

\section{Multivariate Analysis}

In using the comparison of means procedure, several variables cannot be controlled at the same time to allow the statistically robust analysis of the relative influence of migration characteristics on fertility. It is therefore more appropriate to test the interrelations using a more dynamic procedure. In addition to providing a measure of the relative influence of migration as one of the factors affecting CEB when other variables are controlled, multivariate analysis is robust enough to encompass small sample sizes. It can also provide a series of analyses that can permit examination and assessment of the influence of migration process on fertility behaviour when migration is variously measured and/or controlled.

In particular, the procedure is used to identify factors important for explaining the influence on fertility levels as a result of migration. The Ordinary Least Squares regression using the same variables, but changing the index of measurement of migration status, is used to capture or give insight into the varied characteristics of migration process on fertility. In addition, the factors important in influencing fertility levels when migration status categories are controlled are also identified. The findings from the different regression models thus complement one another and show the complexity of the interrelationship under consideration.

The models comprise first, an examination of fertility proximate variables (marriage, contraceptive use), basic to the understanding of fertility and found to be related to migration process (Model-1). Apart from the proximate variables, controls for the different background characteristics of women are key to the understanding of migration fertility relations (Model-2). In addition, different indices of measuring or defining migration process or status employing step regression analysis approach enables an examination and identification of independent contribution of each of these of variables to fertility levels (Model- 3 and 4).

\section{Findings and Discussions}

\section{Comparison of the Mean Results}

Table 3 presents the unstandardised and age specific standardised measures of fertility for the various migration status and sub-categories. In general, migrants seem to have a higher mean number of children ever born than non-migrants although the difference is not large and narrows considerably using the standardised figures. This may be attributed to the effect of age because migrants are older than the general population. Furthermore, the fertility level of migrants may be influenced by the characteristics of rural- 
rural migrants, migrating for marriage and hence influencing the overall fertility of migrants when combined. However, the fertility patterns between migrants and non-migrants are found to differ within their sub-categories.

Comparison among the different sub-categories show that urban natives have the lowest mean children ever born followed by urban-urban migrants, rural-urban migrants, urban-rural migrants, rural natives and rural-rural migrants in that order. Rural-rural migrants have the highest mean number of children ever born. This may be because women in this group disproportionately undertake 'marriage-migration' because of the persistent cultural support of high fertility still prevalent in the rural areas of Kenya. Urban-rural migrants have a mean number of children ever born falling between rural-urban and rural-rural categories, implying some effect of both origin and destination on fertility behaviour of migrant women. Among the never-migrant categories, rural natives have the highest mean number of children ever born. The existing pattern seems to imply the influence of place of residence and especially place of destination on fertility behaviour; region/province of residence; level of education; ethnicity; contraceptive use; marital status; type of marriage; frequency of marriage; work status and age at first sexual intercourse.

Table-3: Age Standardised Children Ever Born by differentials, 1989

\begin{tabular}{|c|c|c|c|c|}
\hline & \multicolumn{2}{|c|}{ Non-migrants } & \multicolumn{2}{|c|}{ Migrants } \\
\hline & $\begin{array}{l}\text { Unstandar- } \\
\text { dized }\end{array}$ & $\begin{array}{l}\text { Standar } \\
\text { dized }\end{array}$ & $\begin{array}{l}\text { Unstandar } \\
\text {-dized }\end{array}$ & $\begin{array}{l}\begin{array}{l}\text { Standar- } \\
\text { dized }\end{array} \\
\end{array}$ \\
\hline \multicolumn{5}{|l|}{ Migration status } \\
\hline Urban natives & 2.53 & 2.77 & & \\
\hline Rural natives & 3.80 & 3.80 & & \\
\hline Rural - Urban & & & 2.76 & 2.54 \\
\hline Rural - Rural & & & 4.03 & 4.73 \\
\hline Urban - Urban & & & 2.40 & 2.16 \\
\hline Urban - Rural & & & 3.58 & 3.21 \\
\hline \multicolumn{5}{|c|}{ Current place of residence } \\
\hline Urban & 2.53 & 2.77 & 2.67 & 2.44 \\
\hline Rural & 3.80 & 3.80 & 3.98 & 4.46 \\
\hline \multicolumn{5}{|c|}{ Region of residence } \\
\hline Nairobi & 2.25 & 2.58 & 2.63 & 2.45 \\
\hline Central & 3.02 & 3.41 & 3.67 & 3.96 \\
\hline Coast & 3.91 & 3.47 & 3.18 & 2.46 \\
\hline Eastern & 3.52 & 3.58 & 3.76 & 4.41 \\
\hline Nyanza & 4.41 & 4.04 & 3.87 & 3.86 \\
\hline Rift Valley & 3.80 & 3.87 & 3.76 & 4.13 \\
\hline Western & 3.48 & 4.03 & 4.24 & 4.78 \\
\hline \multicolumn{5}{|l|}{ Education level } \\
\hline No education & 5.78 & 4.09 & 4.44 & 6.09 \\
\hline Primary & 3.18 & 3.83 & 3.95 & 3.92 \\
\hline Secondary $(+)$ & 1.76 & 2.54 & 2.57 & 2.26 \\
\hline \multicolumn{5}{|l|}{ Ethnicity } \\
\hline Kalenjin & 4.15 & 4.06 & 3.14 & 3.69 \\
\hline Kamba & 3.36 & 3.55 & 3.41 & 3.82 \\
\hline Kikuyu & 3.00 & 3.35 & 3.56 & 3.90 \\
\hline Kisii & 4.18 & 4.13 & 3.69 & 3.16 \\
\hline
\end{tabular}


http://aps.journals.ac.za

34 African Population Studies Vol. $20 N^{\circ}$ 2/Etude de la population africaine vol. $20 n^{\circ} 2$

\begin{tabular}{|c|c|c|c|c|}
\hline Luhya & 3.46 & 3.91 & 4.28 & 4.68 \\
\hline Luo & 4.24 & 3.86 & 3.80 & 3.62 \\
\hline Meru/Embu & 3.71 & 3.71 & 4.24 & 4.24 \\
\hline Miji/Swahili & 4.29 & 4.29 & 3.44 & 3.44 \\
\hline Other & 3.10 & 3.10 & 3.51 & 3.51 \\
\hline \multicolumn{5}{|l|}{ Contraceptive use } \\
\hline Never used & 3.18 & 3.60 & 3.62 & 3.60 \\
\hline Traditional method & 3.73 & 3.73 & 3.86 & 4.20 \\
\hline Modern method & 5.02 & 4.02 & 4.00 & 4.68 \\
\hline \multicolumn{5}{|l|}{ Marital status } \\
\hline Never married & 0.5 & 1.78 & 1.47 & 0.67 \\
\hline Married & 5.20 & 4.20 & 4.10 & 4.68 \\
\hline Widowed & 6.55 & 4.39 & 4.07 & 6.06 \\
\hline Divorced/separated & 2.88 & 2.70 & 2.86 & 3.40 \\
\hline \multicolumn{5}{|l|}{ Marital types } \\
\hline Polygyny & 5.63 & 4.31 & 4.01 & 5.02 \\
\hline Monogamy & 5.06 & 4.22 & 4.14 & 4.59 \\
\hline \multicolumn{5}{|c|}{ Number of times married } \\
\hline Once & 5.10 & 4.14 & 4.09 & 4.64 \\
\hline More than once & 5.24 & 3.86 & 3.42 & 4.50 \\
\hline \multicolumn{5}{|l|}{ Age at first marriage } \\
\hline$<15$ & 6.11 & 4.93 & 4.89 & 5.94 \\
\hline $15-19$ & 5.04 & 4.42 & 4.20 & 4.61 \\
\hline $20-24$ & 4.46 & 3.26 & 3.11 & 3.97 \\
\hline $25+$ & 4.21 & 2.76 & 2.77 & 3.74 \\
\hline \multicolumn{5}{|l|}{ Work status } \\
\hline Not working & 3.68 & 3.77 & 3.91 & 4.18 \\
\hline Working & 3.36 & 3.07 & 2.86 & 3.15 \\
\hline \multicolumn{5}{|c|}{ Age at first sexual intercourse } \\
\hline $8-14$ & 5.00 & 4.29 & 4.23 & 4.58 \\
\hline $15-25$ & 3.91 & 3.54 & 3.59 & 4.01 \\
\hline $26-33$ & 2.08 & 1.29 & 0.10 & 1.39 \\
\hline
\end{tabular}

\section{Children Ever Born by Differentials}

In general, within each of the residential categories, the standardised mean number of children ever born is higher for the migrants than the nonmigrants. Rural regions have higher fertility relative to urbanised regions For instance Nairobi Province has the lowest mean number of children ever born while Western Province has the highest. The fertility levels of other provinces fall in between. Furthermore, irrespective of education status, migrants have a higher mean number of children ever born than nonmigrants. Ethnicity has also been found to be one of the underlying factors in differentiating fertility behaviour among different ethnic groups and regions in Kenya. Among those who are using modern contraceptive, migrants have higher mean number of children ever born than non-migrants.

Migrants have a higher fertility than non-migrants in the never-married category. However, among the married and widowed category, nevermigrants had the highest fertility. In both polygynous and monogamous categories, never-migrants have higher mean number of children ever born than migrants. 
Never-migrant women who have married more than once are found to have a higher fertility than those who have married once. Migrants who work have a lower mean number of children ever born than never-migrants who work. However, among the not working category, non-migrants have the lower mean number of children ever born.

There is evidence in the literature suggesting that migration may interfere with sexual behaviour and patterns among women or couples because of the move itself, or due to the circumstances of their move such as during the settling in period (Goldstein and Goldstein, 1983). However, migration has been found to result in the relaxation of cultural and/or customary restrictions on sexual behaviour (Brockerhoff and Yang, 1995). The effect of migration on sexual behaviour may depend on the extent to which migrants effectively replace the traditions and/or restrictions.

\section{The Regression Results}

Table- 4 shows that marriage is positively related to fertility level, whereas age at first marriage is inversely related with children ever born. Women who marry late lose many potential years of childbearing, including probably the most fecund years, especially if the delay extends to the midtwenties. Women who have married more than once or are in polygynous relationships have more children than those who have married only once or are in monogamous relationships.

However, evidence in the subsequent models, where background characteristics and migration status variables are controlled, shows that being in polygamous unions or having married more than once is negatively related to fertility levels. This may mean that the effects of being in a polygamous marriage or marrying more than once are similar, with the effect of the background variables and migration characteristics that may interfere with fertility behaviour. For instance, migration and education are positively related, but negatively related to fertility. Women in polygamous marriage and those who have married more than once may have low fertility due to lack of consistency and timing of their mating cycles, either because of competition for offspring among co-wives or because of a period of lack of a mating partner coupled with migratory activities. Other possible reasons could be because of reduced exposure risks between marriages or the waiting time before re-marriage. Furthermore, the mean number of sexual acts in a month is directly related to children ever born, implying the desire for more children (Brockerhoff and Yang, 1995).

Contraceptive practice is found to be associated with increasing number of children ever born. Women who are currently using a method of contraception have 0.65 more children than those who are not using any method. This may suggest that high parity common in Kenya may constitute the stimulus for the practice of family planning. Current users may do so for spacing of births, and few for terminating childbearing. However, 
36 African Population Studies Vol. $20 N^{\circ}$ 2/Etude de la population africaine vol. $20 n^{\circ} 2$

controlling for background and migration status variables does not change the pattern of interaction between the proximate variables and fertility.

Table-4 Ordinary Least Squares (OLS) Regression of children Ever Born among women 15-49 years old, KDHS 1989

\begin{tabular}{|c|c|c|c|c|}
\hline Variable & Model1 & Model2 & Model3 & Model4 \\
\hline $\begin{array}{l}\text { Marital status } \\
\text { Never dissolved } \\
\text { Ever dissolved (RC }\end{array}$ & $0.465^{* * *}$ & $1.013^{* * *}$ & $1.019^{* * *}$ & $1.026^{* * *}$ \\
\hline Age at marriage & $-0.173^{* * *}$ & $-.166^{* * *}$ & $-.156^{* * *}$ & $-.159^{* * *}$ \\
\hline $\begin{array}{l}\text { Number of times } \mathbf{n} \\
\text { More than once } \\
\text { Once (RC) }\end{array}$ & $\begin{array}{c}\text { narried } \\
0.083\end{array}$ & $-.654^{* * *}$ & $-.651^{* * *}$ & $-.670^{* * *}$ \\
\hline $\begin{array}{l}\text { Types of marriage } \\
\text { Polygyny } \\
\text { Monogamy (RC) }\end{array}$ & $0.461^{* * *}$ & $-.299^{* * *}$ & $-.297^{* * *}$ & $-.285^{* * *}$ \\
\hline $\begin{array}{l}\text { Contraceptive use } \\
\text { Yes } \\
\text { No (RC) }\end{array}$ & $0.656^{* * *}$ & $.416^{* * *}$ & $.418^{* * *}$ & $.433^{* * *}$ \\
\hline $\begin{array}{l}\text { Education attainm } \\
\text { Primary } \\
\text { Secondary } \\
\text { Tertiary } \\
\text { No-education (RC) }\end{array}$ & & $\begin{array}{l}-.105 \\
-.721^{* * *} \\
-.594\end{array}$ & $\begin{array}{l}-.104 \\
-.716^{* * *} \\
-.579\end{array}$ & $\begin{array}{l}-.119 \\
-.746^{* * *} \\
-.551\end{array}$ \\
\hline $\begin{array}{l}\text { Place of residence } \\
\text { Urban } \\
\text { Rural (RC) }\end{array}$ & & $-.760^{* * *}$ & $-.748^{* * *}$ & $\mathrm{n} / \mathrm{a}$ \\
\hline $\begin{array}{l}\text { Region/Province } \\
\text { Nairobi } \\
\text { Central } \\
\text { Coast } \\
\text { Eastern } \\
\text { Nyanza } \\
\text { Rift Valley } \\
\text { Western (RC) }\end{array}$ & & $\begin{array}{l}-.302 \\
-.083 \\
-.082 \\
-.159 \\
-.079 \\
-.269^{*}\end{array}$ & $\begin{array}{l}-.338 \\
-.110 \\
-.134 \\
-.223 \\
-.121 \\
-.290^{*}\end{array}$ & $\begin{array}{l}-.762^{* * *} \\
-.136 \\
-.465^{*} \\
-.196 \\
-.209 \\
-.323^{*}\end{array}$ \\
\hline $\begin{array}{l}\text { Ethnicity } \\
\text { Kalenjin } \\
\text { Kamba } \\
\text { Kikuyu (RC) } \\
\text { Kisii } \\
\text { Luo } \\
\text { Meru/Embu } \\
\text { Miji/Swahili } \\
\text { Somali } \\
\text { Other }\end{array}$ & & $\begin{array}{l}-.184 \\
-.515^{*} \\
-.349^{*} \\
.026 \\
-.376^{*} \\
-.299 \\
-.708^{* *} \\
-.907 \\
-.932^{* * *}\end{array}$ & $\begin{array}{l}-.234 \\
-.495^{*} \\
-.337^{*} \\
.006 \\
-.367^{*} \\
-.290 \\
-.724^{* * *} \\
-.893 \\
-.955^{* * *}\end{array}$ & $\begin{array}{l}-.194 \\
-.521^{*} \\
-.311^{*} \\
.102 \\
-.341^{*} \\
-.311 \\
-.512^{*} \\
-.750 \\
-.930^{* * *}\end{array}$ \\
\hline $\begin{array}{l}\text { Work status } \\
\text { Yes } \\
\text { No }(R C)\end{array}$ & & -.120 & -.120 & -.152 \\
\hline
\end{tabular}




\begin{tabular}{|c|c|c|c|c|}
\hline \multicolumn{5}{|l|}{ Age } \\
\hline \multicolumn{2}{|l|}{$15-19$} & $-6.548^{* * *}$ & $-6.539^{* * *}$ & $-6.504^{* * *}$ \\
\hline \multicolumn{2}{|l|}{$20-29$} & $-4.362^{* * *}$ & $-4.354^{* * *}$ & $-4.339^{* * *}$ \\
\hline \multirow{2}{*}{\multicolumn{2}{|c|}{$\begin{array}{l}30-39 \\
40-49(\mathrm{RC})\end{array}$}} & $-1.672^{\star * *}$ & $-1.668^{\star * *}$ & $-1.661^{* * *}$ \\
\hline & & & & \\
\hline \multicolumn{5}{|c|}{ Migration indices } \\
\hline Migrant & & & & -.097 \\
\hline \multicolumn{5}{|c|}{ Non-rmigrant (RC) } \\
\hline \multicolumn{5}{|c|}{ c) Migration types } \\
\hline \multicolumn{5}{|c|}{ i) migrant } \\
\hline Rural -urban & & & & $-.554^{* * *}$ \\
\hline Urban-urban & & & & $-.768^{* * *}$ \\
\hline Urban-rural & & & & $-.561^{* *}$ \\
\hline \multicolumn{5}{|l|}{ Rural-rural (RC) } \\
\hline Adj. $\mathbf{R}^{2}$ Square & 0.064 & 0.525 & 0.5525 & 0.525 \\
\hline Constant & 7.273 & 10.077 & 10.135 & 10.174 \\
\hline No. of cases & 4882 & 4882 & 4882 & 4822 \\
\hline
\end{tabular}

\section{Associations among the Selected Background Variables and Fertility}

The proximate variables and background characteristics (Model-2) explain a large proportion of the observed difference in the level of children ever born. Education level is inversely related to children ever born, although there appears to be a minimal difference between women with no education and those with primary education. Women with secondary education on average have about 0.70 fewer children than those with no education, higher even than the difference between those with tertiary education and noeducation. Urban residence is associated with significantly lower fertility. Moreover, place of residence and education levels have been found in several studies to be intricately linked to female status, which inversely relates to fertility levels. Their significant inverse relationship with the level of CEB suggests that improving the status of Kenyan women is conducive to lowering fertility levels in the country. In addition, ethnic patterns are reminiscent of the regional characteristics and patterns. Work status, although showing the expected direction of relationship, is not significantly related with fertility levels in all the models.

\section{Associations among Migration Status Categories and Fertility}

The major concern of this study is how migration relates to fertility (Model3). Using non-migrant women as the reference category, the regression coefficient suggests that migration has a negative but non-significant relation with fertility. However, significant negative relationships appear when migration streams are used for measurement (Model-4). The highest effect on fertility levels is found among the urban-urban migrants. This is 
consistent with other research findings that found that residential characteristics are important factors influencing fertility behaviours and levels (Hervitz, 1985). Thus, change and exposure to new environment and/or residence may have some influence on fertility.

Migration status in general, and when measured as streams, shows a negative and statistically significant association with the fertility. It is important, therefore, to identify the factors related to fertility within different migration status categories.

\section{Migration Status Categories as Correlates of Fertility Levels}

The findings of the first part of this paper are that migration contributes to some of the explained variance in CEB. The unique combination of the characteristics of women migrants may also help to understand the existing fertility patterns and levels. Migrant women in time may show the same fertility behaviour as non-migrants at their destination. In addition, theories that explain the interactions between migration process and fertility behaviour either specifically or implicitly, state that migration may affect fertility levels due to the different contextual differences or the characteristics and behaviour of migrants women before and/or after migration or due to the effect of migration per se. It is therefore important to identify the factors responsible for the existing relationship and patterns of fertility due to migration among the different migration status categories.

\section{Non-migrants' Characteristics as Correlates of Children Ever Born}

Model-1 shows that marital status, age at marriage and contraceptive use are highly associated with CEB. Similar pattern of relationship with the proximate variables is maintained when the background characteristics are controlled. Among the background characteristics, age, education (secondary), region of residence (Nairobi, Eastern and Rift Valley), ethnicity (Other) significantly lower the level of fertility. In addition, ethnic Kalenjin have a significant positive association with $\mathrm{CEB}$, a pointer to the existing cultural practices and influence among the generally traditional and culturally impervious Kalenjin community.

\section{Conclusion}

The study has revealed a clear fertility differential between migrants and non-migrants even when region of residence, ethnicity, education levels, contraceptive use and marital status are held constant. Studies have shown that there exist differences between migrant and non-migrant women in the fertility proximate variables of marriage, contraception and the related background factors. In this paper, these same characteristics have been found to affect the extent to which migration is associated with the differentials in fertility levels. Analyses using bivariate and multivariate 
procedures have produced results to support the following observations and conclusions.

\section{The Bivariate Results}

At a gross level, indications are obtained from the average number of children ever born as the primary index of fertility by migration status categories. For each residence category, within specific age groups, urban migrants have a lower mean number of children ever born than rural migrants. This pattern is sustained even when the data are standardized for age, although the magnitude of the difference is reduced and is small overall. Comparison within the different migration status groups also indicates that urban natives have the lowest fertility levels among nonmigrants, whereas amongst migrants, urban-urban migrants have the lowest mean number of children ever born. Rural-rural migrants have the highest mean number of children ever born.

These findings suggest that fertility is more a function of particular residential characteristics, especially the place of destination. Fertility is low in urban than rural areas, and many of the urban inhabitants are migrants. The behavioural characteristics of women by different migration categories may also imply the operation of selective characteristics of women in relation to the nature of their migration destination.

In addition, migrants in each of the residence categories have fertility only slightly above that of the non-migrants, as indicated by the standardized rates, in the same residential location. This may suggests that either migrants adapt to the fertility norms and behaviour of the place of destination or they may have been selected by their characteristics which may be similar to or perceived by migrants to be similar to the fertility behaviour and characteristics of the destinations.

Other characteristics demonstrating differences in fertility levels due to the influence of migration status include: region of residence, ethnic variations, education levels, contraceptive behaviour, marital characteristics, work status, and sexual behaviour. Migrants to rural regions have a higher mean number of children ever born than migrants to urban regions. The fertility levels of migrants by different ethnic groups support the above pattern. Comparison of fertility levels of migrants by education levels shows that migrants with secondary plus education have the lowest levels; and that migrants using modern contraceptives have a lower mean number of children ever born than never-migrants using same methods. Women who migrate are in general more modern in their attitude, and more innovative in their desire to control their fertility than their non-migrants counterparts. In addition, migrants are obliged, influenced or motivated by the circumstances of their destination.

Married and widowed migrant categories have the lowest mean number of children ever born. Migration seems to disrupt marital behaviour, which 
is an important fertility determining factor. Migration is positively related to polygyny and the number of times a women has been married (once or more than once). These characteristics have been noted to have inherent disruptive effect on the reproductive pattern and behaviour of women. Migrants also have a higher age at first marriage than non-migrants. Migrants marry relatively late compared to their non-migrant counterparts, which may culminate in lower fertility levels. Migration may also be a selective response to inability to find a new partner locally. Migrant women who work have lower fertility than those who do not work; lower than even those of never-migrant women who work. This supports findings from other studies that migration and work status contribute to lower levels of fertility.

\section{Multivariate Results}

In general, the effects of the background and intermediate variables on fertility are similar in direction, if not in degree or significance for each measure of migration used (model -1 and model -2). The results demonstrate that education and fertility are negatively related; and that urban women have on average fewer children than do those in the rural areas. Work status shows a slight negative association with fertility levels, but the relationship is non-significant; and fertility is negatively related to contraceptive use. The results show lower fertility as age at marriage rises: late age at marriage reduces the period of exposure to the risk of pregnancy. In addition, marital status (ever married) is associated with higher fertility.

Using non-migrants as reference category, regression results show that migration has negative effect on fertility. However, for migration status as defined used in Model-3, there does not seem to be a significant negative influence on mean number of children ever born. The greatest variation $\left(\mathrm{R}^{2}\right)$ appears when migration is measured using different streams (Model-4). This may be because of confounding factors between different migration streams. Although it would appear that contribution of migration itself is small in relation to the total variance explained by the background variables and the fertility intermediate variables (model-2), model-3 seems to suggest that unique contribution of migrant women to fertility levels may help to understand the observed fertility behaviour and characteristic among the migrants.

\section{The Effect of Migration Streams on Fertility}

Several theories about the relations between migration and fertility either specifically or implicitly state that migration has effect on fertility. The underlying assumption of these theories is that migrants find themselves in milieus substantially different from their place of origin and far removed from values and norms that characterise their previous residence. Destinations may either have been chosen because of the contextual differentials or may affect migrant behaviour subsequent to the move. 
Additionally, the disparities between origin and destination may have been sufficiently great to disrupt normal behaviour such as childbirth for some time after the migration. The relation is best understood by giving attention to streams of movements.

Model-4 results show that migration between different types of residence has significant negative affect on the mean number of children ever born. This may suggest the underlying influence of residential characteristics on fertility behaviour and levels. Urban-urban migration characteristics show the highest influence on fertility levels, with the lowest variations associated with rural-rural migration. The magnitude of variation may also suggest the importance of the place of origin in determining fertility behaviour. The results of the magnitude and direction of the association between migration and children ever born confirm the significance of migration process and also identify the unique combinations of the characteristics and direction of the migration categories that influence fertility.

\section{References}

Anker, R. and J.C Knowles. 1982. Fertility Determinants in Developing Countries: A Case of Kenya. Ordina: Liege, Belgium.

Arnold, F. and A.K. Blanc. 1990. Fertility Levels and Trends, DHS Comparative Studies 2, Institute for Resource Development, Colombia, MD.

Bongaarts, J. 1982. 'Fertility Determinants'. In International Encyclopaedia of Population, J.A. Ross (ed.).The Free Press, New York, pp. 275-79.

Bongaarts, J. 1978. A Framework for Analysing the Proximate Determinants of Fertility, Population and Development Review, 4 (1): 105-132.

Brass, W. and C.L. Jolly (eds.), 1993. Population Dynamics of Kenya. Committee on Population, National Academy Press, Washington, D.C.

Brockerhoff, M. 1990. Rural-to-urban Migration and Child Survival in Senegal, Demography, 27: 601-615.

Brockerhoff, M. and Hongsook, Eu. 1993. Demographic and Socio-economic Determinants of Female Rural to Urban Migration in Sub-Saharan Africa, International Migration Review, 27: 557-77.

Brockerhoff, M. and X.Yang. 1995 Impact of Migration on Fertility in Sub-Saharan Africa, Social Biology, 41 (1-2): 19-43.

Findley, S. 1982. Fertility and Migration, In International Encyclopaedia of Population, J.A. Ross (ed.). The Free Press, New York, pp. 247-52.

Goldstein, S. and A. Goldstein. 1983. Migration and Fertility in Peninsular Malaysia: an Analysis Using Life History Data, Rand Corporation Note, N-1860-AID.

Hervitz, H. M. 1985. Selectivity, Adaptation, or Disruption? A Comparison of Alternative Hypotheses on the Effects of Migration on Fertility: the Case of Brazil, International Migration Review 19 (2): 293-317.

Kenya Government. 1989. Demographic and Health Survey, 1989. National Council for Population and Development, Ministry of Home Affairs and National Heritage, Nairobi.

Robinson, W.C. 1992. Kenya enters the fertility transition, Population Studies, 46: 44557. 
42 African Population Studies Vol. $20 N^{\circ}$ 2/Etude de la population africaine vol. $20 n^{\circ} 2$

Robinson, W.C. and S.F Harbison. 1995. Toward a unified theory of fertility. In Demographic Behaviour: Interdisciplinary Perspectives on Decision-making, T.K. Burch (ed.). Westview Press, Boulder, Colorado.

United Nations. 1984. Population Distribution, Migration and Development, Population Studies, No. 89. United Nations, New York.

Wortham, R. 1995. Prospects for Fertility Reduction and Projections for Future Population Growth in Kenya, Population Research and Policy Review, 14: 111-135. 